\title{
Correlation of serum levels of HIF-I $\alpha$ and IL-19 with the disease progression of COPD: a retrospective study
}

This article was published in the following Dove Press journal: International Journal of COPD

\author{
Biaoxue Rong' \\ Yufang Liu ${ }^{2}$ \\ $\mathrm{Min} \mathrm{Li}^{3}$ \\ Tian $\mathrm{Fu}^{4}$ \\ Wenlong $\mathrm{Gao}^{5}$ \\ Hua Liu \\ 'Department of Respiratory \\ Medicine, First Affiliated Hospital, \\ Xi'an Medical University, Xi'an, \\ China; ${ }^{2}$ Comprehensive Medicine \\ Department, Shenmu Hospital, \\ Shenmu, China; ${ }^{3}$ Department of \\ Respiratory Medicine, Shenmu \\ Hospital, Shenmu, China; ${ }^{4}$ Department \\ of Respiratory Medicine, Jining No \\ I People's Hospital, Jining, China; \\ ${ }^{5}$ Institute of Epidemiology and Health \\ Statistics, School of Public Health, \\ Lanzhou University, Lanzhou, China; \\ ${ }^{6}$ Department of Respiratory Medicine, \\ Gansu Provincial Hospital, Lanzhou, \\ China
}

Background: The aim of this study was to disclose the correlation between the serum levels of hypoxia-inducible factor 1 alpha (HIF-1 $\alpha$ ) and IL-19 and stable COPD.

Methods: The serum levels of HIF-1 $\alpha$ and IL-19 were tested by ELISA. The relationships between their levels and clinical parameters of stable COPD patients were analyzed by linear regression methods.

Results: Patients with stable COPD showed higher serum levels of HIF- $1 \alpha$ and IL-19 compared with healthy control group $(P<0.001)$, and serum levels of HIF-1 $\alpha$ and IL-19 had a positive linear correlation $(P<0.05)$. In stable COPD patients, increased serum levels of HIF-1 $\alpha$ and IL-19 were positively correlated with the GOLD grading $(P<0.005)$, modified British Medical Research Council (mMRC) score $(P<0.05)$, and medical history $(P<0.05)$ but negatively related to the pulmonary function $(P<0.05)$. The serum level of HIF-1 $\alpha(P<0.05)$ was affected by the patient's $\mathrm{FEV}_{1} / \mathrm{FVC}$ value and COPD grading, and the serum level of IL-19 was associated with the mMRC scores and the serum level of HIF-1 $\alpha(P<0.05)$.

Conclusion: Increased serum levels of HIF- $1 \alpha$ and IL-19 correlated with the disease progression of COPD, suggesting that they can be used as indicators to help us understand the COPD.

Keywords: chronic obstructive pulmonary disease, COPD, hypoxia-inducible factor 1 alpha, interleukin-19, serum, pulmonary function

\section{Introduction}

COPD is characterized by persistent airflow limitation and acute exacerbations and is associated with cardiovascular complications, ${ }^{1}$ which leads to a high incidence among the elderly. ${ }^{2}$ Airflow limitation is usually gradual and is associated with chronic inflammatory response. ${ }^{3}$ The pathological mechanism of the COPD is still unknown. The more accepted doctrines include the hypothesis of protease and antiproteinase, the hypothesis of oxidation and antioxidant imbalance, and the immune and inflammatory hypothesis. ${ }^{4}$ Among them, the immune and inflammatory is the focus of current clinical research. It has been found that more than 50 kinds of cytokines are involved in the pathogenesis of COPD..$^{5-7}$ Hypoxia-inducible factor 1 alpha (HIF-1 $\left.\alpha\right)$ is a major regulator of oxygen homeostasis and regulates the pathophysiology of hypoxia. ${ }^{8}$ Studies have shown that HIF-1 $\alpha$ and its downstream vascular endothelial growth factor genes may be associated with COPD. ${ }^{9}$ Hypoxia can induce continuous expression of HIF- $1 \alpha$ and promote pulmonary vascular remodeling and aggravate the course of COPD. ${ }^{10,11}$ IL-19 can be detected in human monocytes, ${ }^{12}$ and the expression of IL-19 can be enhanced by stimulating B and T lymphocytes. ${ }^{13}$ Studies show that increased IL-19 is involved in the incidence of autoimmune disease ${ }^{12}$ such as psoriasis, asthma, and
Correspondence: Biaoxue Rong Department of Respiratory Medicine, First Affiliated Hospital, Xi'an Medical University, 48 Fenghao West Road,

Xi'an 710077, China

Tel +862987679300

Email research568rbx@yeah.net 
rheumatoid arthritis by upregulating pro-inflammatory cytokines. ${ }^{14}$ Monocytes treated by IL-19 induce the production of IL-6, tumor necrosis factor- $\alpha$ (TNF- $\alpha$ ), and reactive oxygen metabolites, which play a pro-inflammatory role in the development of COPD. ${ }^{15}$

However, the serum expression and clinical significance of HIF- $1 \alpha$ and IL-19 in the COPD are still unclear. In this study, we tested the serum expression levels of the HIF- $1 \alpha$ and IL-19 in stable COPD patients and analyzed the correlations between their levels and the clinical parameters of COPD.

\section{Methods}

\section{Research objects}

From January 2015 to December 2017, 80 confirmed patients with stable COPD with an average age of $68.96 \pm 6.56$ years were recruited in the study (Gansu Provincial Hospital, Lanzhou, China; First Hospital, Xi' an Medical University, Xi'an, China; Department of Respiratory Medicine, Jining No 1 People's Hospital, Jining, China; and Shenmu Hospital, Shenmu, China). Blood samples from 51 healthy elderly individuals (outpatient examination) were collected. These individuals, with an average age of $66.98 \pm 6.53$ years, comprised the control group. Clinical information is shown in Table 1. No significant differences on age, gender, and smoking status (the smoking patients included in this study were all active smokers) were found between the COPD and control groups $(P>0.05)$.

\section{Diagnostic criteria of COPD}

COPD patients were confirmed according to the diagnostic criteria of Global Initiative for Chronic Obstructive Lung Disease $\left.(G O L D)^{16,17}: 1\right)$ chronic cough, phlegm, progressive dyspnea, and history of exposure to COPD risk factors (even if there are no symptoms of respiratory distress); 2) after treating by bronchodilator, the value $\mathrm{FEV}_{1} / \mathrm{FVC}$ was less than 0.70. Definition for stable COPD is as follows: the patient's cough, expectoration, and shortness of breath are in stable condition or just show a mild symptoms or the condition is basically restored to the state before acute exacerbation. ${ }^{18}$

\section{Inclusion criteria of stable COPD patients} Inclusion criterion were as follows: 1) met the GOLD's diagnostic criteria for stable COPD and completed lung function testing; ${ }^{18}$ 2) antibiotics, glucocorticoid, theophylline drugs, and oxygen therapy were not used within the 2 weeks; 3 ) not accompanied by purulent sputum, fever, and increase
Table I Clinical information and general data of included patients (80 cases)

\begin{tabular}{l|l|l|l}
\hline Items & Classification & $\begin{array}{l}\text { COPD group } \\
(\mathbf{N}, \%)\end{array}$ & $\begin{array}{l}\text { Control group } \\
\mathbf{( N ,} \%)\end{array}$ \\
\hline Gender & Male & $49(6 I .3)$ & $22(43.1)$ \\
Age (years) & Female & $31(38.7)$ & $29(56.9)$ \\
& $<70$ & $36(45)$ & $30(58.8)$ \\
$\geq 70$ & $44(55)$ & $21(41.2)$ \\
Pack years of & $>40$ & $28(35)$ & $15(29.4)$ \\
smoking & $20.1-40$ & $10(12.5)$ & $6(11.8)$ \\
& $0.1-20$ & $3(3.8)$ & $1(1.9)$ \\
GOLD grade & 0 & $39(48.7)$ & $29(56.9)$ \\
& 1 & $5(6.2)$ & \\
& 2 & $16(20)$ & \\
mMRC score & 3 & $32(40)$ & \\
& 4 & $27(33.8)$ & \\
Clinical history & 2 & $11(13.8)$ & \\
(years) & 3 & $35(43.7)$ & \\
& $\geq 10$ & $34(42.5)$ & \\
\hline
\end{tabular}

Notes: GOLD grade: I=FEV $\%$ predicted is greater than or equal to $80 \%, 2=\mathrm{FEV}, \%$ predicted is greater than or equal to $50 \%$, but less than $80 \%, 3=\mathrm{FEV} \%$ predicted is greater than or equal to $30 \%$, but less than $50 \%$, and $4=\mathrm{FEV}_{1} \%$ predicted is less than $30 \%$; mMRC, dyspnea scale for symptom classification of COPD.

Abbreviations: GOLD, Global Initiative for Chronic Obstructive Lung Disease; mMRC, modified British Medical Research Council for dyspnea scale for symptom classification of COPD.

of white blood cell count or neutrophils percentage; 4) no radiographic evidence of pneumonia. Radiographic evidence of pneumonia was defined as the presence of consolidation (a dense or fluffy opacity with or without air bronchograms), other infiltrates (linear and patchy alveolar or interstitial densities), or pleural effusion, ${ }^{19}$ and 5) the patient provided informed consent.

\section{Exclusion criteria}

Exclusion criteria were as follows: 1) acute exacerbation of COPD; 2) combined with interstitial lung disease, asthma, tuberculosis, pneumonia, bronchial pneumonia, lung cancer, and other pulmonary organic disease; 3) combined with diabetes, hypertension, and severe cardiovascular, cerebrovascular, and neurological diseases or liver and kidney dysfunction; and 4) combined with mental illness, cognitive dysfunction, and communication obstacles.

\section{Severity grading for COPD}

We determined the grading of COPD according to the criterion of GOLD, ${ }^{18,20}$ which were shown as follows: 1) GOLD- $1, \mathrm{FEV}_{1} \%$ predicted is greater than or equal to $80 \%$; 2) GOLD-2, the $\mathrm{FEV}_{1} \%$ predicted is greater than or equal to 
$50 \%$, but less than $80 \%$; 3) GOLD-3, the $\mathrm{FEV}_{1} \%$ predicted is greater than or equal to $30 \%$, but less than $50 \%$; and 4 ) GOLD-4, the $\mathrm{FEV}_{1} \%$ predicted is less than $30 \%$.

\section{Blood collection}

Blood was collected from the patient's elbow vein and numbered according to the order of enrollment. The serum was separated by centrifuging at 3,000 rpm for 10 minutes and then was stored under $-80^{\circ} \mathrm{C}$. The frozen serum was defrosted at room temperature when testing.

\section{ELISA}

The expression levels of HIF-1 $\alpha$ and IL-19 in serum were measured by sandwich-type ELISA that was originally developed using rabbit anti-human HIF-1 $\alpha$ and IL-19 antibodies. The assay was performed following the directions given by the manufacturer (HIF-1 $\alpha$ product Code: bsk00388, IL-19 product Code: F01490; Xitang Biotechnology Co. Ltd, Shanghai, China). Briefly, the samples, standard products, and HRP-labeled detection antibodies were successively added to the embedding microporous of the captured antibody. After warm breeding and thorough washing, a tetramethylbenzidine coloring liquid was used to perform chromogenic reaction. The color intensity was measured at a wavelength of $450 \mathrm{~nm}$ using a photometer. The standard curve was plotted based on the concentration of the standard sample and the optical density of each well.

\section{Evaluation of subjective efficacy}

Dyspnea of patients was evaluated by the modified British Medical Research Council (mMRC) scale, which consists of five statements. ${ }^{21}$ Grade 0: I only get breathless with strenuous exercise; Grade 1: I get short of breath when hurrying on level ground or walking up a slight hill; Grade 2: On level ground, I walk slower than people of the same age because of breathlessness, or I have to stop for breath when walking at my own pace on the level; Grade 3: I stop for breath after walking about 100 yards or after a few minutes on level ground; Grade 4: I am too breathless to leave the house or I am breathless when dressing. ${ }^{21}$

\section{Evaluation of objective efficacy}

The lung function of a patient was tested three times at different times; an average of three measurements was considered as a test data. The selected measurement items in this study included $\mathrm{FEV}_{1} / \mathrm{FVC}$ and $\mathrm{FEV}_{1} \%$ predicted, which are directly related to the diagnosis and classification of COPD.

\section{Ethics statement}

This study was a nonintervention retrospective study. All patients were approached based on approved ethical guidelines, and the patients signed the informed consent form before entering into the study. The study was approved by Research Ethics Committees of research institutes (Gansu Provincial Hospital, Lanzhou, China; First Hospital, Xi'an Medical University, Xi'an, China; Jining No 1 People's Hospital, Jining, China; and Shenmu Hospital, Shenmu, China). We state that all methods were performed in accordance with the relevant guidelines and regulations.

\section{Statement for strengthening the reporting of observational studies in epidemiology (STROBE)}

Readers should be able to easily identify the design through the title or abstract. The explicit, commonly used term in this study also helps ensure correct indexing of articles in electronic databases. The sample size, study variables, and observations are clearly described in this study. An intention to treat analysis and a bias analysis of result report were also conducted.

\section{Statistical methods}

SPSS 21.0 statistical software was used to perform data analysis. The count data are expressed in terms of constituent ratio (\%), and the measurement data are expressed as mean $\pm \mathrm{SD}(\mathrm{X} \pm \mathrm{S})$. The comparison on the count data was performed using chi-squared test and on the measurement data using one-way analysis of variance. If the overall variance of each group was not homogeneous according to the test of variance homogeneity of variance, the Brown-Forsythe method is used. The $q$-test was used to compare the scores of each group, and the Pearson correlation was used for correlation analysis. Linear regression and multiple linear regression analyses were performed to determine the correlation between a dependent variable and several independent variables. Statistical significance was set at $P<0.05$.

\section{Results}

Patients with stable COPD show a higher serum level of HIF-I $\alpha$ compared with control group

As shown in Table 2, serum level of HIF-1 $\alpha$ was significantly higher in patients with stable COPD $(91.9 \pm 20.4 \mathrm{pg} / \mathrm{mL})$ than that in those of the control group $(63.2 \pm 16.8 \mathrm{pg} / \mathrm{mL})$ $(P<0.001)$ (Figure 1A). 
Table 2 Relationship between clinical parameters and the level of HIF-I $\alpha$ in serum of stable COPD patients $(n=80)$

\begin{tabular}{|c|c|c|c|c|c|c|}
\hline \multirow[t]{2}{*}{ Parameter } & \multirow[t]{2}{*}{ Group } & \multirow[t]{2}{*}{$\mathbf{N}$} & \multicolumn{4}{|c|}{ Level of HIF-I $\alpha$ in serum of stable COPD patients } \\
\hline & & & Value $(\mathbf{M} \pm \mathbf{S D} \mathrm{pg} / \mathrm{mL})$ & Degrees of freedom & Statistical value & $P$-value \\
\hline \multirow[t]{2}{*}{ Resources } & Control & 51 & $63.2 \pm 16.8$ & 129 & 6.976 & $<0.001$ \\
\hline & Stable COPD & 80 & $91.9 \pm 20.4$ & & & \\
\hline \multirow[t]{2}{*}{ Gender } & $10.332 \mathrm{pt}$ & 49 & $90.9 \pm 20.0$ & 78 & -0.526 & 0.600 \\
\hline & Female & 31 & $93.4 \pm 21.2$ & & & \\
\hline \multirow[t]{2}{*}{ Age (years) } & $<70$ & 36 & $90.6 \pm 20.0$ & 78 & -0.510 & 0.612 \\
\hline & $\geq 70$ & 44 & $92.9 \pm 20.6$ & & & \\
\hline \multirow[t]{4}{*}{ Pack years of smoking } & $>40$ & 28 & $94.1 \pm 16.1$ & 78 & 0.631 & 0.392 \\
\hline & $20.1-40$ & 10 & $90.2 \pm 19.3$ & & & \\
\hline & $0.1-20$ & 3 & $88.2 \pm 21.7$ & & & \\
\hline & 0 & 39 & $89.9 \pm 22.6$ & & & \\
\hline \multirow[t]{4}{*}{ GOLD grade } & 1 & 5 & $85.8 \pm 25.8$ & 3 & 7.115 & $<0.001$ \\
\hline & 2 & 16 & $90.7 \pm 12.4$ & & & \\
\hline & 3 & 32 & $103.6 \pm 22.9^{\star}$ & & & \\
\hline & 4 & 27 & $114.3 \pm 14.9^{\star}$ & & & \\
\hline \multirow[t]{3}{*}{ mMRC score } & 2 & 11 & $85.6 \pm 15.5$ & 2 & 5.373 & 0.007 \\
\hline & 3 & 35 & $105.8 \pm 21.3^{\star \star}$ & & & \\
\hline & 4 & 34 & $106.9 \pm 18.7^{\star \star}$ & & & \\
\hline \multirow[t]{3}{*}{ Medical history (years) } & $<10$ & 27 & $94.9 \pm 18$ & 2 & 5.062 & 0.009 \\
\hline & $\geq 10$ to $<20$ & 23 & $103.3 \pm 25.2$ & & & \\
\hline & $\geq 20$ & 30 & $111.4 \pm 15.6^{\star \star \star}$ & & & \\
\hline
\end{tabular}

Notes: ${ }^{\star}$ The level of HIF-I $\alpha$ in stable COPD patients with GOLD grades 3 and 4 was significantly higher than that in patients with GOLD grades I and 2 . $\star$ The patients with mMRC scores of 3 and 4 showed a higher expression level of serum HIF-I $\alpha$ than those with mMRC score of $2{ }^{\star \star \star}$ The expression of serum HIF-I $\alpha$ in the patients with a longer history was also upregulated compared to those with relatively short history.

Abbreviations: GOLD, Global Initiative for Chronic Obstructive Lung Disease; HIF-I $\alpha$, hypoxia-inducible factor I alpha; mMRC, modified British Medical Research Council.
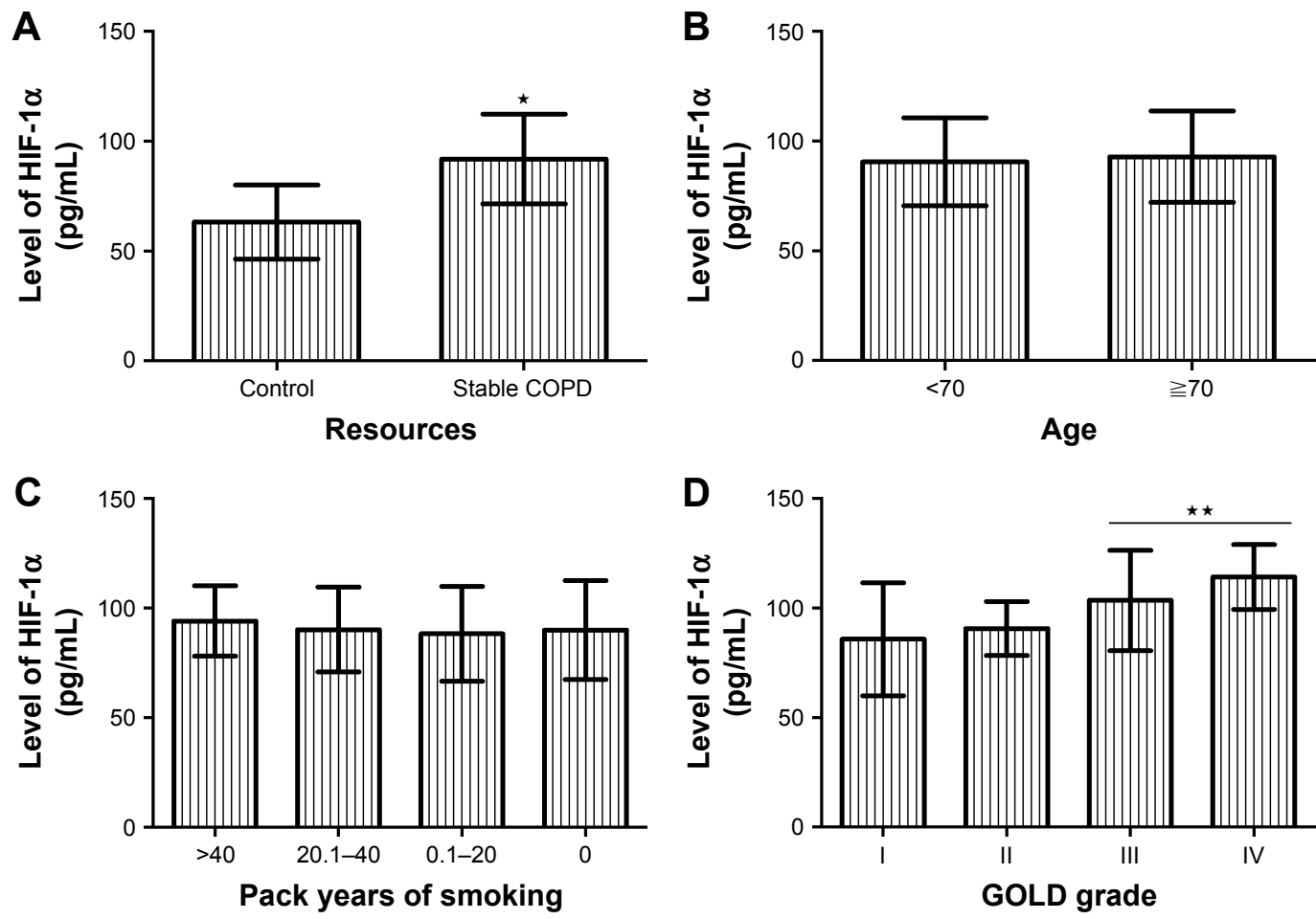

Figure I (Continued) 

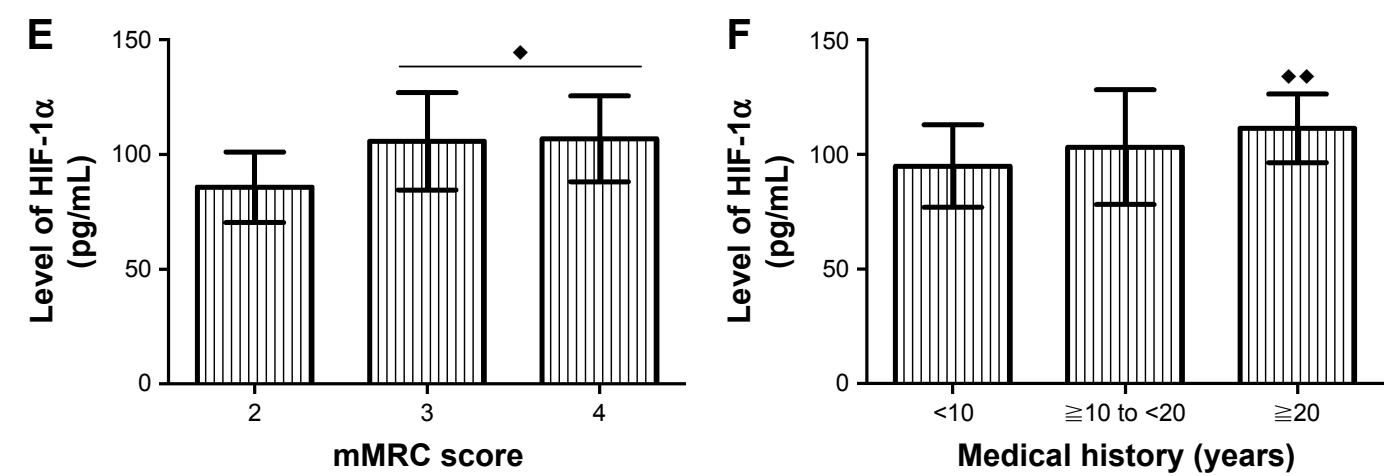

Figure I Relationship between the clinical parameters and serum level of HIF-I $\alpha$ in stable COPD patients.

Notes: (A) ^Patients with stable COPD showed a higher expression of serum HIF-I $\alpha$ compared with control group $(P<0.00 \mathrm{I})$. (B) Serum HIF-I $\alpha$ expression did correlate with the patient's age $(P=0.6 \mid 2)$. (C) Serum HIF-I $\alpha$ expression did correlate with the patient's smoking status $(P=0.392)$. (D) ${ }^{\star \star}$ serum HIF-I $\alpha$ level of patients with GOLD 3 and 4 was increased compared with that of GOLD I and $2(P<0.00 \mathrm{I})$. (E) •The patients with mMRC scores of 3 and 4 showed a higher serum level of HIF-I $\alpha$ compared with those with mMRC score of $2(P=0.007)$. (F) ${ }^{\bullet}$ Serum HIF-I $\alpha$ in the patients with longer clinical history was increased compared to those with short history $(P=0.009)$.

Abbreviations: HIF-I $\alpha$, hypoxia-inducible factor I alpha; GOLD, Global Initiative for Chronic Obstructive Lung Disease; mMRC, modified British Medical Research Council.

\section{Increase of serum HIF-I $\alpha$ is positively correlated with the GOLD grade, mMRC score, and clinical history of patients}

As shown in Table 2, serum level of HIF-1 $\alpha$ was not associated with gender, age, and smoking status of COPD patients $(P>0.05$; Figure 1B and C). However, the serum level of
HIF-1 $\alpha$ in patients with GOLD $3(103.6 \pm 22.9 \mathrm{pg} / \mathrm{mL})$ and $4(114.3 \pm 14.9 \mathrm{pg} / \mathrm{mL})$ was higher than that in those with GOLD $1(85.8 \pm 25.8 \mathrm{pg} / \mathrm{mL})$ and $2(90.7 \pm 12.4 \mathrm{pg} / \mathrm{mL})$ $(P<0.001$; Figure 1D). The patients with mMRC scores of $3(105.8 \pm 21.3 \mathrm{pg} / \mathrm{mL})$ and $4(106.9 \pm 18.7 \mathrm{pg} / \mathrm{mL})$ showed a higher level of serum HIF-1 $\alpha$ compared with

Table 3 Relationship between the clinical parameters and the serum level of IL- 19 in stable COPD patients $(n=80)$

\begin{tabular}{|c|c|c|c|c|c|c|}
\hline \multirow[t]{2}{*}{ Parameter } & \multirow[t]{2}{*}{ Group } & \multirow[t]{2}{*}{$\mathbf{N}$} & \multicolumn{4}{|c|}{ Level of IL- 19 in serum of stable COPD patients } \\
\hline & & & Value $(\mathbf{M} \pm \mathbf{S D} \mathrm{pg} / \mathrm{mL})$ & Degrees of freedom & Statistical value & $P$-value \\
\hline Resources & $\begin{array}{l}\text { Control } \\
\text { Stable COPD }\end{array}$ & $\begin{array}{l}51 \\
80\end{array}$ & $\begin{array}{l}43.1 \pm 12.6 \\
70.2 \pm 16.6\end{array}$ & 129 & -6.223 & $<0.001$ \\
\hline Gender & $\begin{array}{l}\text { Male } \\
\text { Female }\end{array}$ & $\begin{array}{l}49 \\
31\end{array}$ & $\begin{array}{l}70.5 \pm 17.9 \\
69.8 \pm 14.2\end{array}$ & 78 & 0.202 & 0.841 \\
\hline Age (years) & $\begin{array}{l}<70 \\
\geq 70\end{array}$ & $\begin{array}{l}36 \\
44\end{array}$ & $\begin{array}{l}66.8 \pm 17.2 \\
72.9 \pm 15.7\end{array}$ & 78 & -1.671 & 0.099 \\
\hline Pack years of smoking & $\begin{array}{l}>40 \\
20.1-40 \\
0.1-20 \\
0\end{array}$ & $\begin{array}{l}28 \\
10 \\
3 \\
39\end{array}$ & $\begin{array}{l}74.2 \pm 16.9 \\
71.8 \pm 16.1 \\
72.4 \pm 17.9 \\
66.9 \pm 15\end{array}$ & 78 & 0.56 & 0.110 \\
\hline GOLD grade & $\begin{array}{l}1 \\
2 \\
3 \\
4\end{array}$ & $\begin{array}{l}5 \\
16 \\
32 \\
27\end{array}$ & $\begin{array}{l}55.3 \pm 11.1 \\
62.7 \pm 17.7 \\
70.1 \pm 15.2^{\star} \\
77.6 \pm 14.9^{\star}\end{array}$ & 3 & 4.874 & 0.004 \\
\hline mMRC score & $\begin{array}{l}2 \\
3 \\
4\end{array}$ & $\begin{array}{l}11 \\
35 \\
34\end{array}$ & $\begin{array}{l}58.6 \pm 14.6 \\
66.3 \pm 15.1 \\
78.4 \pm 15^{\star}\end{array}$ & 2 & 9.453 & $<0.001$ \\
\hline Clinical history (years) & $\begin{array}{l}<10 \\
\geq 10 \text { to }<20 \\
\geq 20\end{array}$ & $\begin{array}{l}27 \\
23 \\
30\end{array}$ & $\begin{array}{l}62.5 \pm 16.6 \\
69.6 \pm 14.9 \\
77.6 \pm 14.7^{\star \star}\end{array}$ & 2 & 6.86 & 0.002 \\
\hline
\end{tabular}

Notes: *The level of IL- 19 in stable COPD patients with GOLD grades 3 and 4 was significantly higher than that in patients with GOLD grades I and 2; $\star$ * Patients with mMRC score of 4 showed a higher expression level of serum IL- 19 than those with mMRC scores of 3 and 2; ${ }^{\star \star}$ The expression of serum IL-19 in patients with long clinical history was also upregulated compared to those with relatively short history.

Abbreviations: GOLD, Global Initiative for Chronic Obstructive Lung Disease; mMRC, modified British Medical Research Council. 
those with mMRC score of $2(85.6 \pm 15.5 \mathrm{pg} / \mathrm{mL})(P=0.007$; Figure 1E). In addition, the serum level of HIF-1 $\alpha$ in patients with long clinical history $(111.4 \pm 15.6 \mathrm{pg} / \mathrm{mL}$ for $\geq 20$ years) was increased compared to that in those with short history $(103.3 \pm 25.2 \mathrm{pg} / \mathrm{mL}$ for history $\geq 10$ to $<20$ years; $94.9 \pm 18 \mathrm{pg} / \mathrm{mL}$ for history $<10$ years $)(P=0.009$; Figure $1 \mathrm{~F})$.

\section{Serum level of IL-19 is increased in stable} COPD patients compared with control

\section{group}

As shown in Table 3, the patients with stable COPD $(70.2 \pm 16.6 \mathrm{pg} / \mathrm{mL})$ showed a higher serum level of IL-19 compared with those in the control group $(43.1 \pm 12.6 \mathrm{pg} / \mathrm{mL})$ $(P<0.001)$ (Figure 2A).
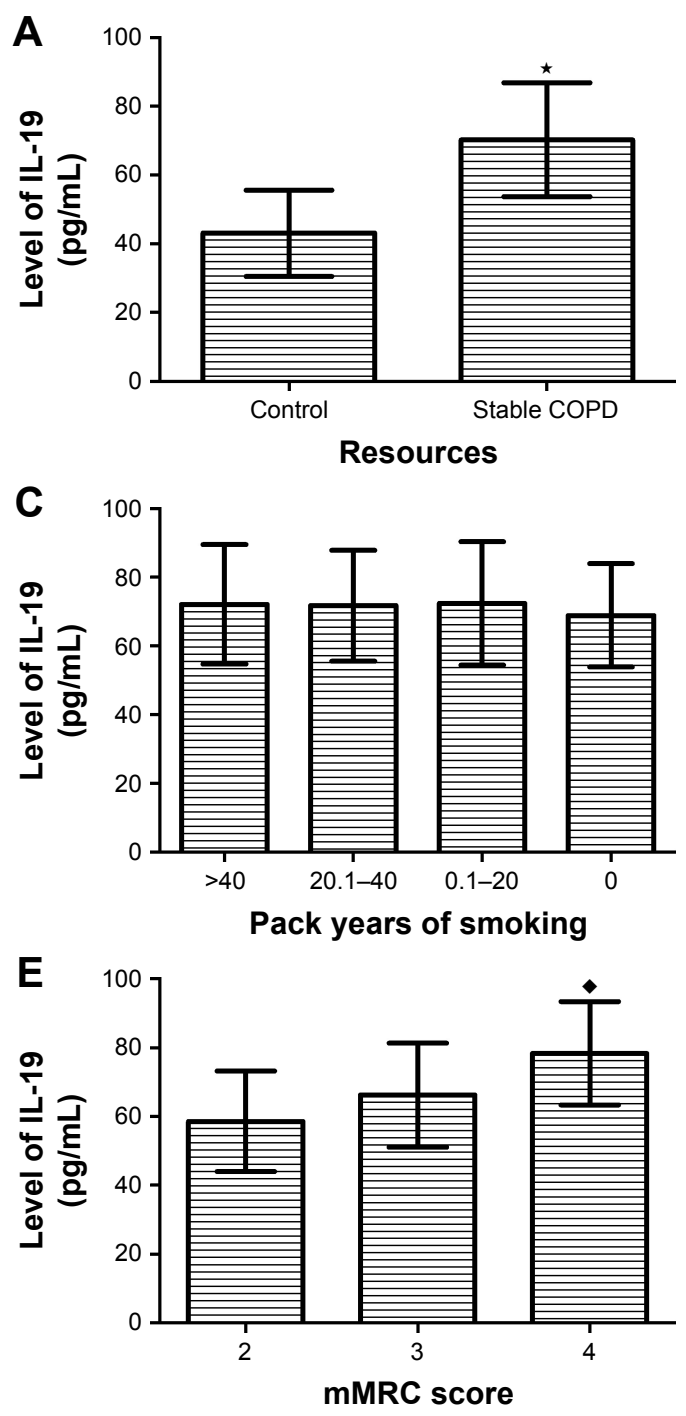

Increase of serum IL-19 is positively correlated with the GOLD grade, mMRC score, and clinical history of patients

As shown in Table 3, serum level of IL-19 was not associated with the COPD patient's gender, age, and smoking status $(P>0.05$; Figure $2 \mathrm{~B}$ and $\mathrm{C})$. However, the serum level of IL-19 in patients with GOLD $3(70.1 \pm 15.2 \mathrm{pg} / \mathrm{mL})$ and $4(77.6 \pm 14.9 \mathrm{pg} / \mathrm{mL})$ was higher than that in those with GOLD $1(55.3 \pm 11.1 \mathrm{pg} / \mathrm{mL})$ and $2(62.7 \pm 17.7 \mathrm{pg} / \mathrm{mL})$ $(P=0.004$; Figure 2D). Compared with the mMRC scores of 2 $(58.6 \pm 14.6 \mathrm{pg} / \mathrm{mL})$ and $3(66.3 \pm 15.1 \mathrm{pg} / \mathrm{mL})$, the patients with the $\mathrm{mMRC}$ score of $4(78.4 \pm 15 \mathrm{pg} / \mathrm{mL})$ showed an upregulation of serum IL-19 $(P<0.001$; Figure 2E). Also, the serum level of IL-19 in patients with long clinical history $(77.6 \pm 14.7 \mathrm{pg} / \mathrm{mL}$
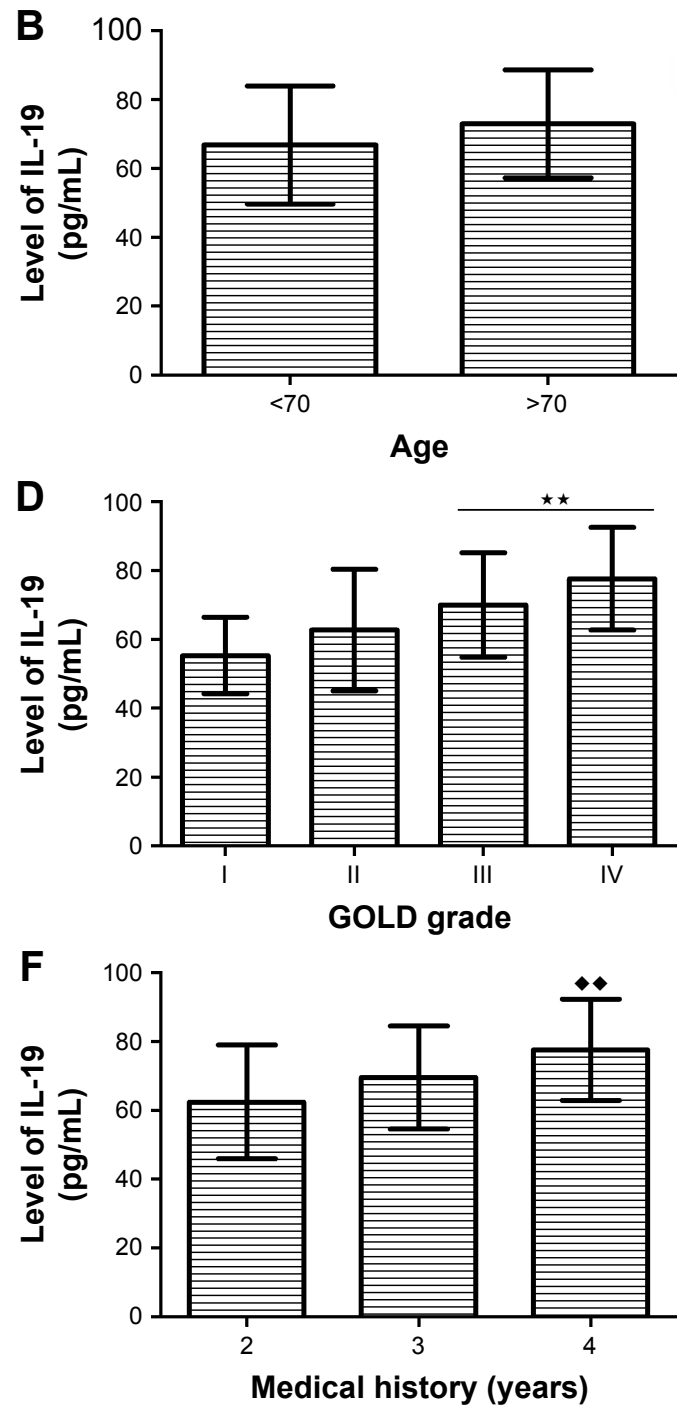

Figure 2 Relationship between the clinical parameters and serum level of IL- 19 in serum of stable COPD patients.

Notes: $(\mathbf{A}){ }^{\star}$ Patients with stable COPD showed a higher expression of serum IL-19 compared with the control group $(P<0.00 \mathrm{I})$. (B) Serum IL-19 expression did correlate with the patient's age $(P=0.84 \mathrm{I})$. (C) Serum IL-19 expression did correlate with the patient's smoking status $(P=0.1$ I 0$)$. (D) ${ }^{\star}$ Serum IL-I9 level of patients with GOLD 3 and 4 of COPD was increased compared with those of GOLD I and $2(P=0.004)$. (E) •The patients with mMRC scores of 3 and 4 showed a higher serum level of IL-I 9 compared with those with $\mathrm{mMRC}$ score of $2(P<0.00 \mathrm{I})$. $(\mathbf{F})$ `Serum IL-19 in patients with longer medical history was increased compared to those with short history $(P=0.002)$.

Abbreviations: GOLD, Global Initiative for Chronic Obstructive Lung Disease; mMRC, modified British Medical Research Council. 
for $\geq 20$ years) was upregulated compared to those with short history $(69.6 \pm 14.9 \mathrm{pg} / \mathrm{mL}$ for history $\geq 10$ to $<20$ years; $62.5 \pm 16.6 \mathrm{pg} / \mathrm{mL}$ for history $<10$ years $)(P=0.002$; Figure $2 \mathrm{~F})$.

\section{Serum levels of HIF-I $\alpha$ and IL-I 9 show a significant linear correlation}

As shown in Table 4, Pearson correlation test showed that the correlation coefficient was $0.347(P=0.001)$ and the F-value was 10.67 ( $P=0.002)$. Coefficient of analysis showed that the regression coefficient was 0.279 ( $\mathrm{T}=3.26, P=0.002 ; 95 \% \mathrm{CI}$ : $0.109-0.339$ ). The results indicated that the levels of HIF- $1 \alpha$ and IL-19 showed a significant linear correlation, and the regression equation was ${ }^{\wedge} Y=41+0.28 X$ (Figure $3 \mathrm{~A}-\mathrm{D}$ ).

\section{Serum level of HIF-I $\alpha$ is negatively correlated with pulmonary function in patients with stable COPD}

As shown in Table 4, the serum level of HIF-1 $\alpha$ was negatively correlated with $\mathrm{FEV}_{1} / \mathrm{FVC}$ (Pearson correlation coefficient $=-0.595, P<0.001$; the $\mathrm{F}$-value of variance analysis $=42.73, P<0.001$; the T-value of correlation coefficient test $=-6.53, P<0.001$; $95 \%$ CI: -115.96 to -61.82 ; the regression equation $\left.=^{\wedge} Y=142-88.89 X\right)($ Figure $4 \mathrm{~A}$ and $\mathrm{B})$ and $\mathrm{FEV}_{1} \%$ predicted (Pearson correlation coefficient $=-0.555$, $P<0.001$; the F-value of variance analysis $=34.64, P<0.001$; the T-value of correlation coefficient test $=-5.88, P<0.001 ; 95 \%$ CI: -85.19 to -42.12 ; the regression equation $\left.={ }^{\wedge} Y=130-63.66 X\right)$ (Figure 4C and D) in stable COPD patients.

\section{Serum level of IL- I 9 is negatively correlated with pulmonary function in patients with stable COPD}

As shown in Table 4, the serum level of IL-19 was negatively correlated with the $\mathrm{FEV}_{1} / \mathrm{FVC}$ (Pearson correlation coefficient $=-0.397, P<0.001 ; \mathrm{F}$ value of variance analysis $=14.59, P<0.001 ; \mathrm{T}$ value of correlation coefficient test $=-3.82, P<0.001 ; 95 \% \mathrm{CI}=-75.58$ to -22.84 ; the regression equation $\left.=^{\wedge} Y=90-47.71 X\right)($ Figure $5 \mathrm{~A}$ and $\mathrm{B})$ and the $\mathrm{FEV}_{1} \%$ predicted (Pearson correlation coefficient $=-0.424$, $P<0.001 ; \mathrm{F}$ value of variance analysis $=17.13, P<0.001$; T value of correlation coefficient test $=-4.13, P<0.001 ; 95 \%$ CI: -58.03 to -20.33 ; the regression equation $={ }^{\wedge} Y=86-39.18 X$ ) (Figure 5C and D) in stable COPD patients.

\section{Serum level of HIF-I $\alpha$ seems to be affected by the value of $F E V, / F V C$ and COPD grading of stable COPD patients}

As shown in Table 5, a stepwise regression showed that the patient's $\mathrm{FEV}_{1} / \mathrm{FVC}(P<0.001 ; 95 \% \mathrm{CI}:-201.58$ to -78.82$)$

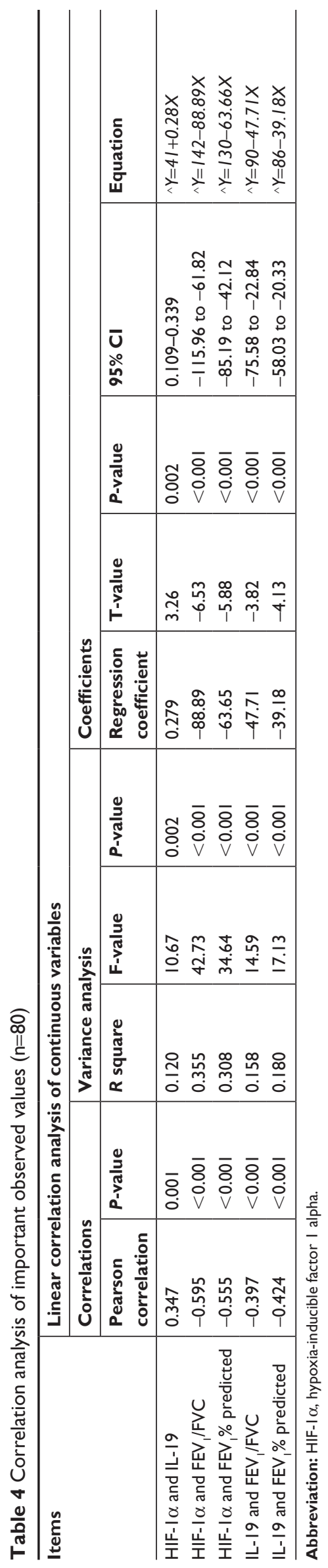


A

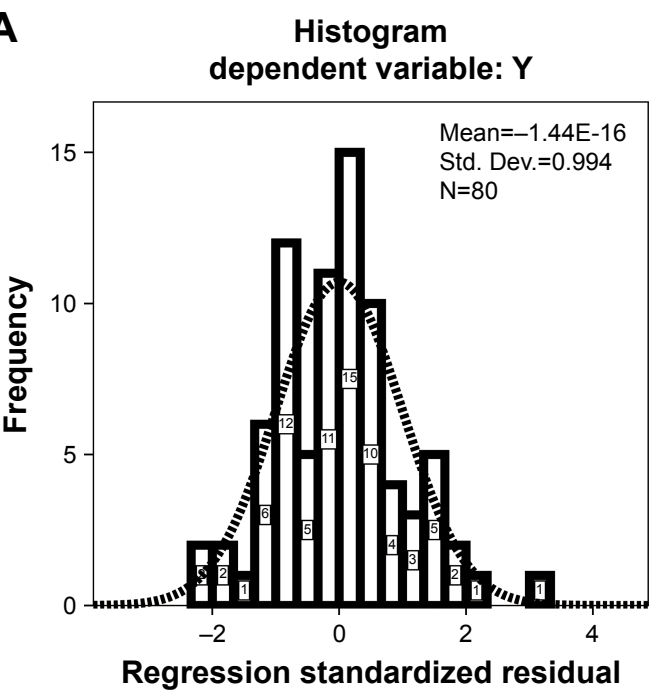

B
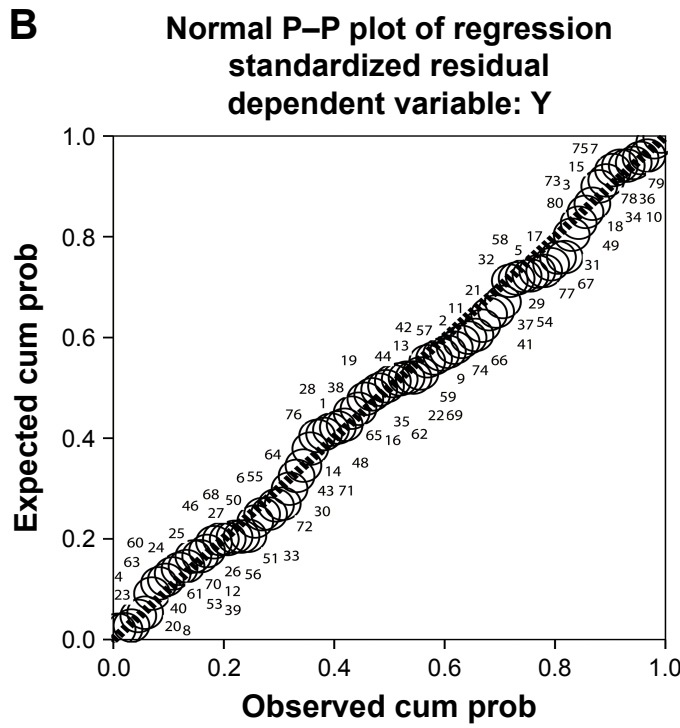

C

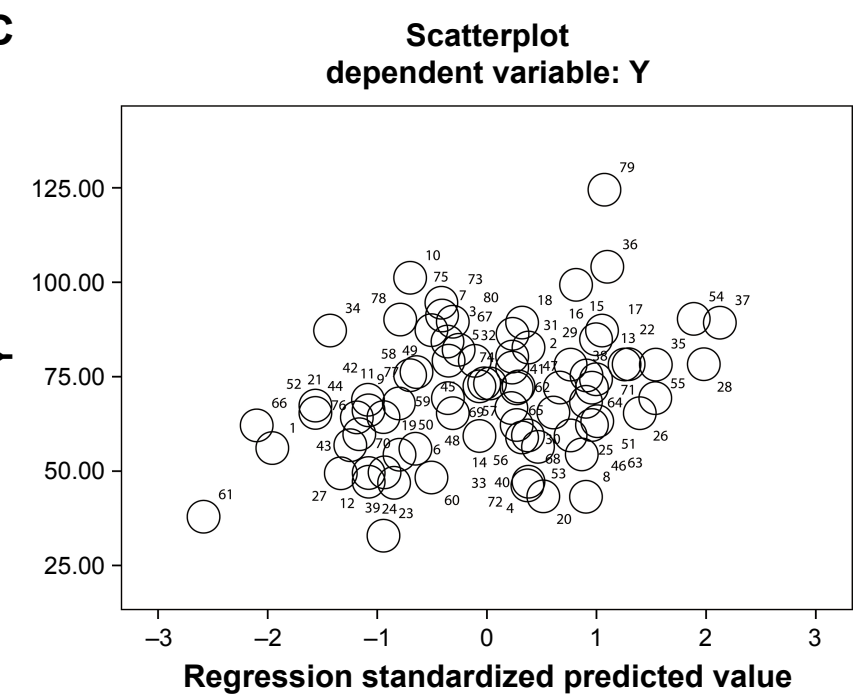

D

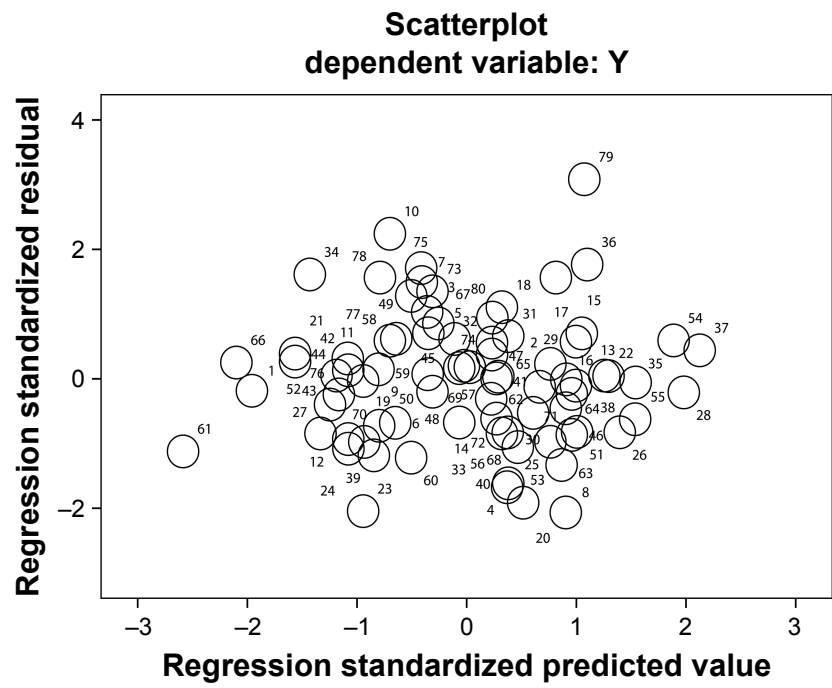

Figure 3 Relationship between serum levels of HIF-I $\alpha$ and IL- 19 in stable COPD patients.

Notes: $(\mathbf{A})$ The histogram of normal curve showed that the normalized residuals are normal distributions $(P>0.05)$. (B) The cumulative probability plot of the observations suggested that the two variables have a feature of normal distribution $(P<0.05)$. (C) The dependent variable is approximately linear with the standardized predictive value, indicating that HIF-I $\alpha$ and IL- 19 have a linear correlation $(P>0.05)$. (D) The vast majority of normalized residuals did not exceed 3 , suggesting no specific value was found. Abbreviations: cum prob, cumulative probability; HIF- I $\alpha$, hypoxia-inducible factor I alpha.

and COPD grading $(P=0.046 ; 95 \%$ CI: 18.34-67.90) seemed to have an influence on the expression of HIF-1 $\alpha$. The influence of $\mathrm{FEV}_{1} / \mathrm{FVC}$ (partial regression analysis=-140.207) on HIF-1 $\alpha$ was greater than that of COPD grading (partial regression analysis $=8.781$ ) (Figure $6 \mathrm{~A}$ and $\mathrm{B})$.

\section{Serum level of IL-19 is correlated with the patient's $m M R C$ scores and the serum level of HIF-I $\alpha$}

As shown in Table 5, stepwise analysis of multiple linear regression showed that the level of IL-19 was likely affected by the patient's mMRC scores $(P<0.001 ; 95 \%$ CI: 4.146-13.829) and the expression of HIF-1 $\alpha(P=0.020$;
95\% CI: 0.031-0.359). The patient's mMRC scores (partial regression analysis $=8.988)$ appeared to have a greater influence than HIF-1 $\alpha$ (partial regression analysis $=0.195$ ) (Figure 6C and D).

\section{Discussion}

The characteristics of COPD are persistent respiratory symptoms and persistent airflow limitation. ${ }^{22}$ In the development of COPD, cytokines and inflammatory mediators play important roles in pathophysiological processes of COPD, including the process of chronic inflammation, the formation of emphysema, and the disturbance of immune function in vivo. ${ }^{23}$ Recent studies have shown that HIF- $1 \alpha$ and IL-19 are 
A
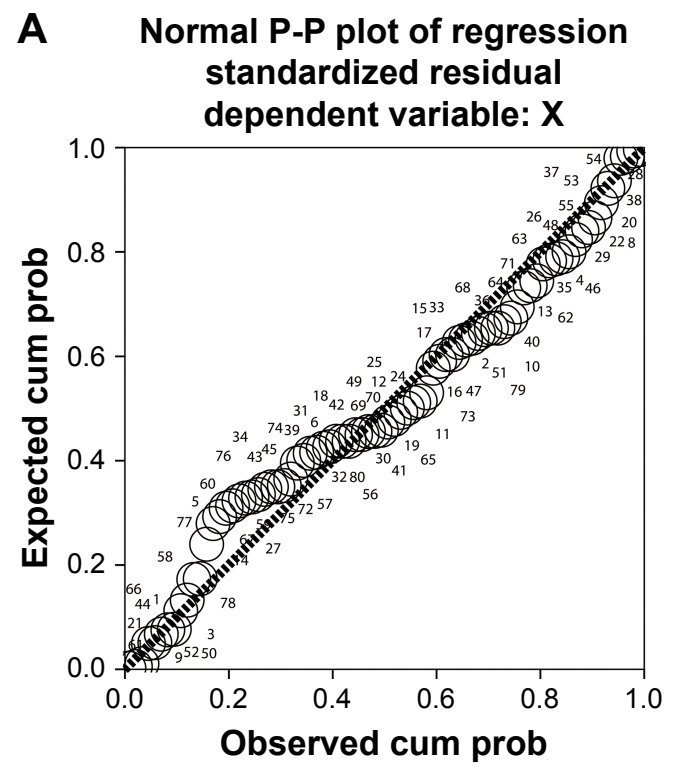

\section{Normal P-P plot of regression standardized residual dependent variable: $\mathbf{X}$}

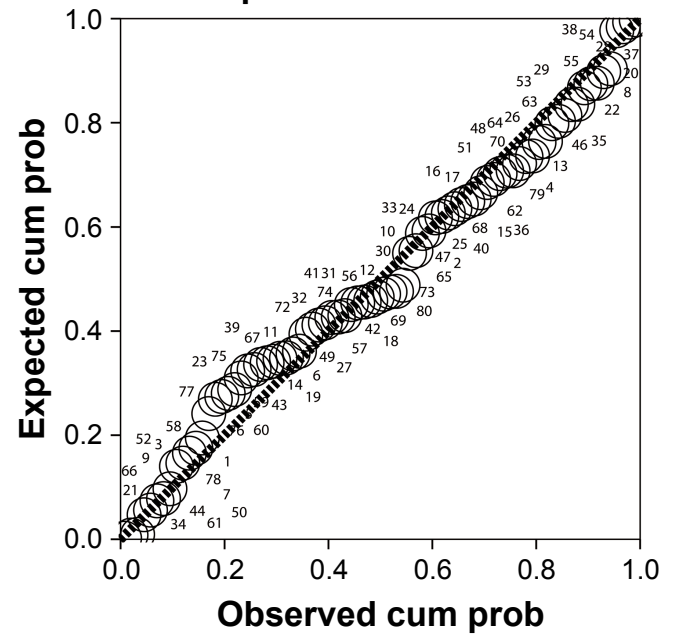

B

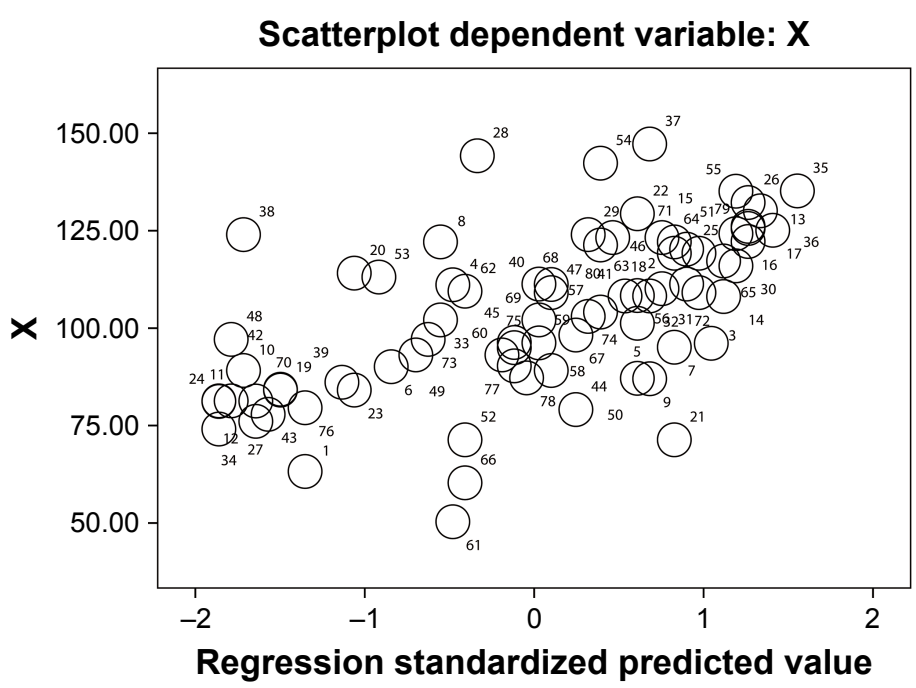

D

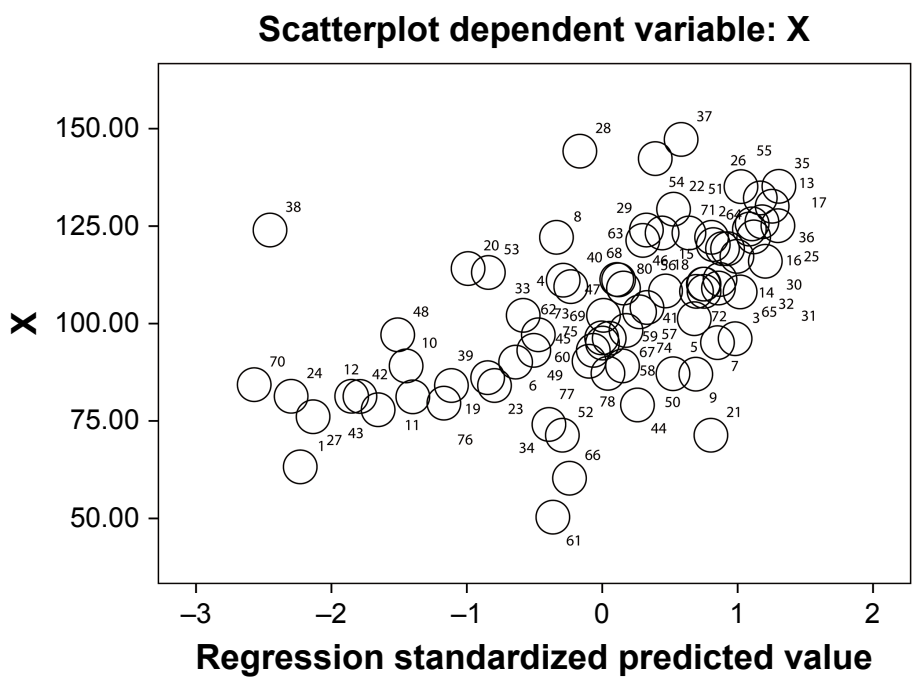

Figure 4 Relationship between serum level of HIF-I $\alpha$ and pulmonary function in patients with stable COPD.

Notes: (A) The scatter point plot for HIF-I $\alpha$ and FEV, $/ F V C$ indicated that the two variables belonged to normal distribution $(P>0.05)$. (B) The dependent variable is approximately linear with the standardized predictive value, indicating that serum HIF-I $\alpha$ and FEV $/ F V C$ of patients have a linear correlation $(P<0.05)$. (C) The scatter point plot for HIF- $I \alpha$ and FEV \% predicted indicated that the two variables belonged to normal distribution (P>0.05). (D) The dependent variable is approximately linear with the standardized predictive value, indicating that serum HIF-I $\alpha$ and $\mathrm{FEV}_{1} \%$ predicted of patients have a linear correlation $(P<0.05)$.

Abbreviations: cum prob, cumulative probability; HIF-I $\alpha$, hypoxia-inducible factor I alpha.

associated with many chronic inflammatory diseases. . $^{8,9,12-15,23}$ We tested the serum levels of HIF-1 $\alpha$ and IL-19 in stable COPD patients and tried to disclose their biological significance in the occurrence and development of COPD. We found that patients with stable COPD showed a higher expression of serum HIF-1 $\alpha$ compared with the control group (healthy elderly) and upregulation of serum HIF-1 $\alpha$ was positively correlated with the GOLD grade, mMRC score, and medical history of patients, which means that the serum level of $\mathrm{HIF}-1 \alpha$ is related to the disease progression of stable COPD.
A recent study has shown that HIF- $1 \alpha$ is a regulatory factor for inflammation, which can be activated by a variety of inflammatory stimuli. ${ }^{24}$ Recent evidence indicates that activation of the HIF-1 $\alpha$ pathway by nuclear factor $\kappa \mathrm{B}(\mathrm{NF}-\kappa \mathrm{B})$ contributes to the development of COPD, and the management of NF- $\mathrm{KB}$ inhibitors may diminish the development of COPD. ${ }^{11} \mathrm{We}$ also found that serum IL-19 was increased in stable COPD compared with control group, and its level also showed a positive correlation with the GOLD grade, mMRC score, and medical history of patients, which indicated that IL-19 


\section{A Normal P-P plot of regression standardized residual dependent variable: $X$}

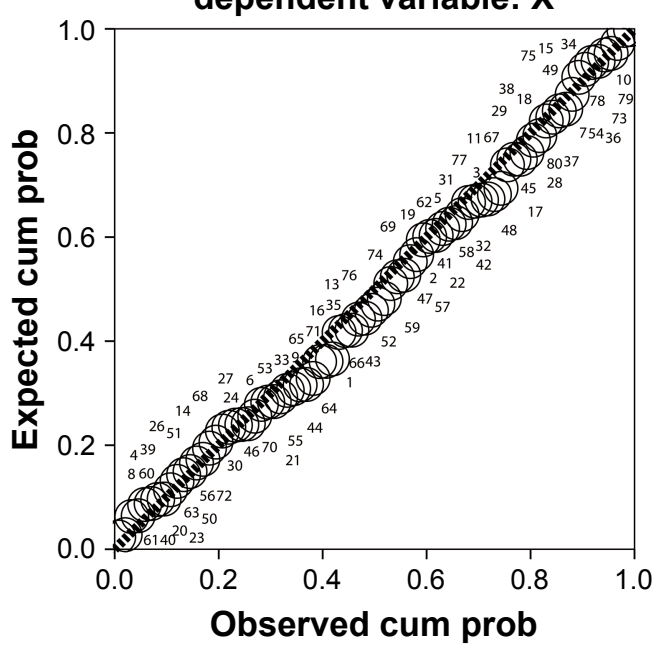

\section{Normal P-P plot of regression standardized residual dependent variable: $X$}

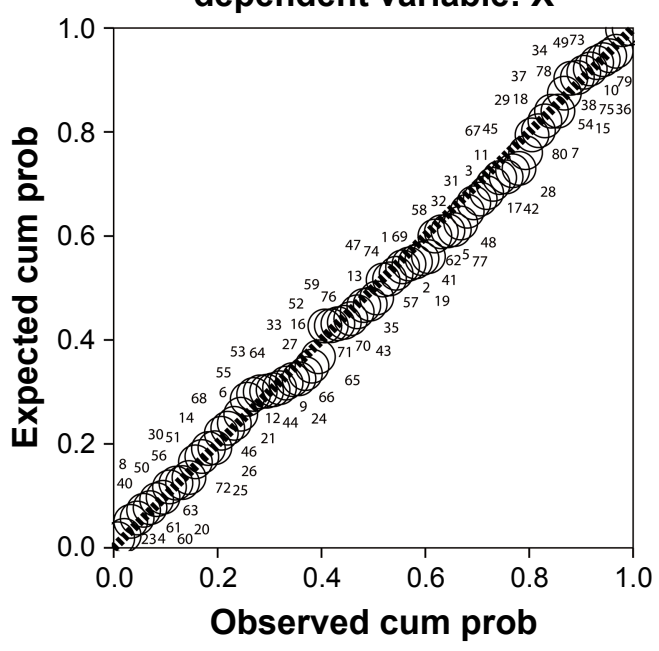

B

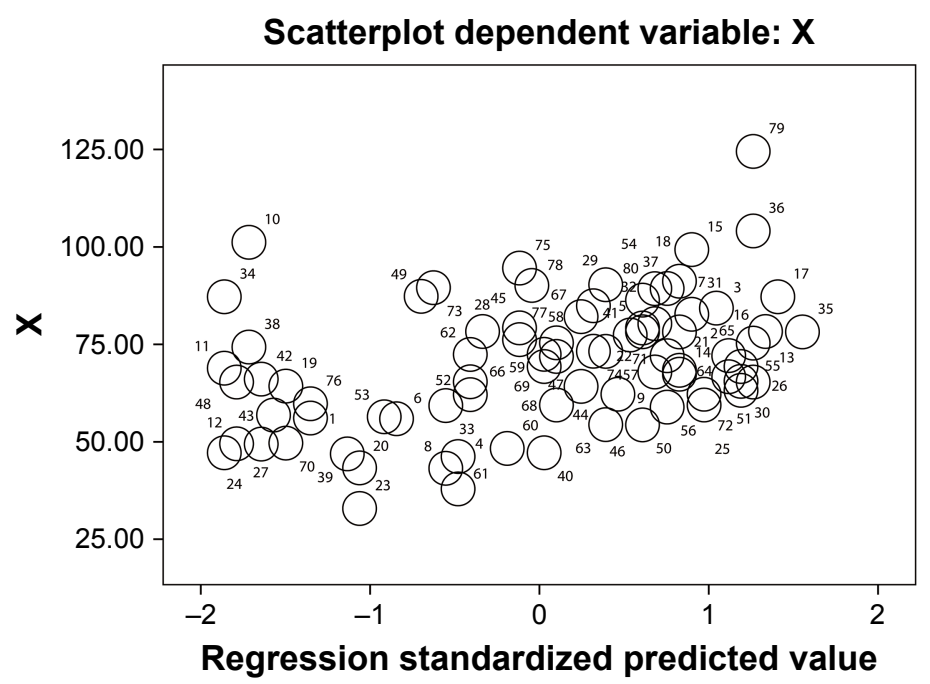

D

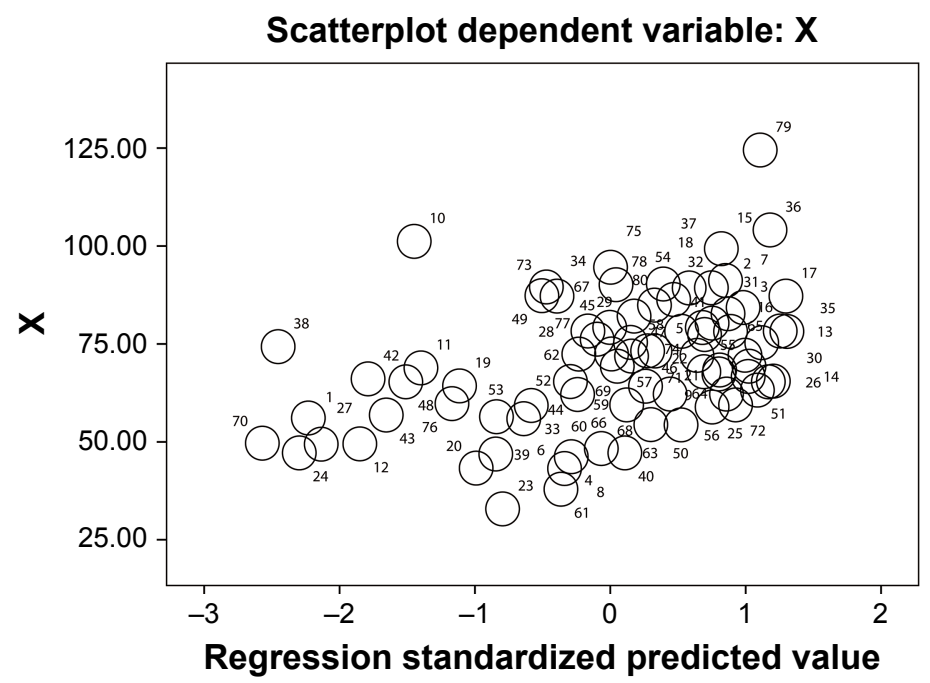

Figure 5 Relationship between the serum level of IL-19 and pulmonary function in patients with stable COPD.

Notes: (A) The scatter point plot for IL-19 and FEV, /FVC indicated that the two variables belonged to normal distribution ( $P>0.05)$. (B) The dependent variable is approximately linear with the standardized predictive value, indicating that serum IL-19 and FEV, IFVC of patients had a linear correlation ( $P<0.05)$. (C) The scatter point plot for IL-19 and FEV \% predicted indicated that the two variables belonged to normal distribution $(P>0.05)$. (D) The dependent variable is approximately linear with the standardized predictive value, indicating that serum IL-19 and $\mathrm{FEV}, \%$ predicted that patients had a linear correlation $(P<0.05)$.

Abbreviation: cum prob, cumulative probability

Table 5 Multiple linear regression analysis to determine the factors that affect the serum levels of HIF-I $\alpha$ and IL- 19 ( $n=80$ )

\begin{tabular}{|c|c|c|c|c|c|c|c|c|c|c|}
\hline & \multirow[t]{3}{*}{ Model } & \multicolumn{9}{|c|}{ Multiple linear regression analysis for HIF-I $\alpha$ and IL-I 9} \\
\hline & & \multicolumn{2}{|l|}{$\begin{array}{l}\text { Unstandardized } \\
\text { coefficients }\end{array}$} & \multicolumn{2}{|c|}{$\begin{array}{l}\text { Variance } \\
\text { analysis }\end{array}$} & \multirow{2}{*}{$\begin{array}{l}\text { Standardized } \\
\text { coefficients } \\
\text { Beta value }\end{array}$} & \multirow[t]{2}{*}{ T-value } & \multirow[t]{2}{*}{$P$-value } & \multicolumn{2}{|c|}{$95 \% \mathrm{Cl}$ for $\mathrm{B}$} \\
\hline & & $\begin{array}{l}\text { Partial regression } \\
\text { analysis (B) }\end{array}$ & $\begin{array}{l}\text { Std. } \\
\text { error }\end{array}$ & F-value & $P$-value & & & & $\begin{array}{l}\text { Lower } \\
\text { bound }\end{array}$ & $\begin{array}{l}\text { Upper } \\
\text { bound }\end{array}$ \\
\hline The factors that & $\mathrm{FEV}_{1} / \mathrm{FVC}$ & $-|40.2|$ & 30.82 & 42.732 & $<0.001$ & -0.938 & -4.56 & $<0.001$ & -201.58 & -78.82 \\
\hline affect HIF-I $\alpha$ & GOLD grading & 8.781 & 4.75 & & & 0.381 & 1.85 & 0.046 & 18.34 & 67.92 \\
\hline The factors that & mMRC scores & 8.988 & 2.431 & 13.033 & $<0.001$ & 0.379 & 3.697 & $<0.001$ & 4.146 & 13.829 \\
\hline affect IL-19 & HIF-I $\alpha$ & 0.195 & 0.082 & & & 0.243 & 2.367 & 0.020 & 0.031 & 0.359 \\
\hline
\end{tabular}

Abbreviations: HIF-I $\alpha$, hypoxia-inducible factor I alpha; mMRC, modified British Medical Research Council; Std., standard. 
A

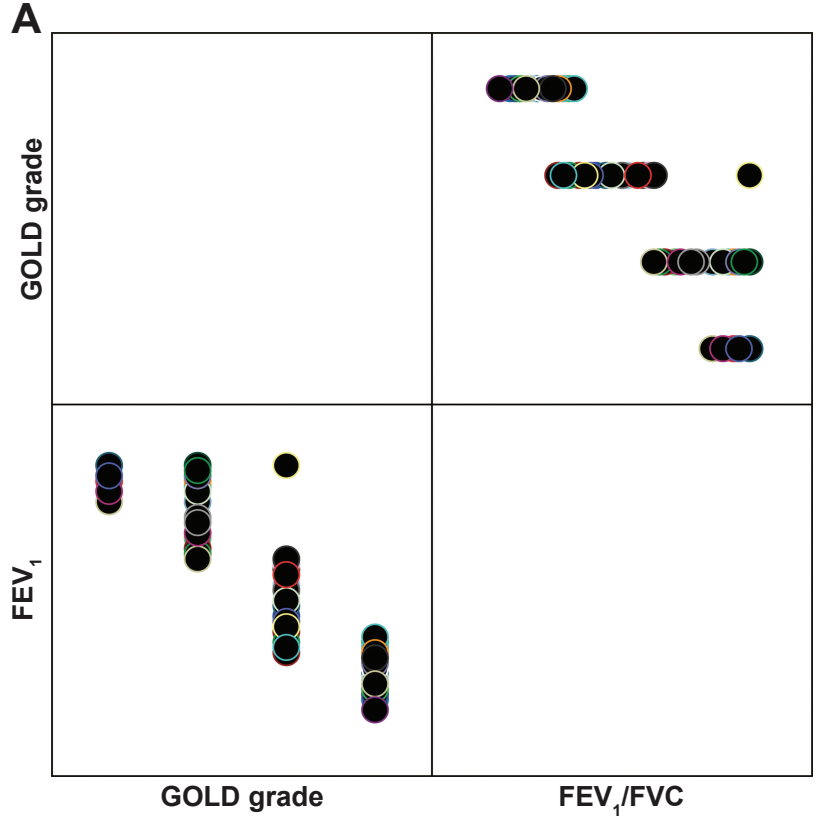

C

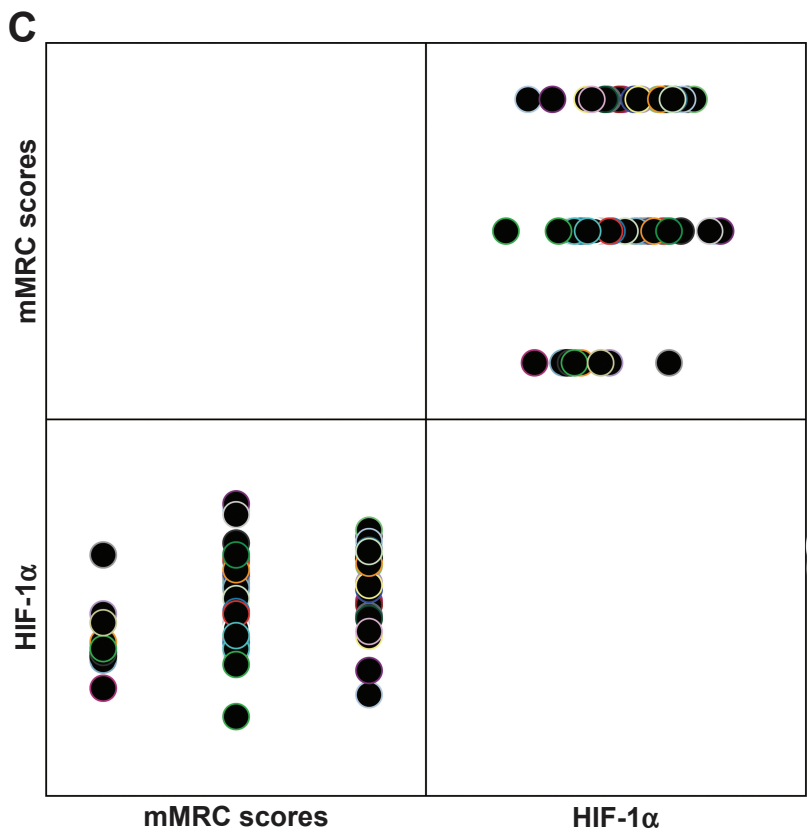

B

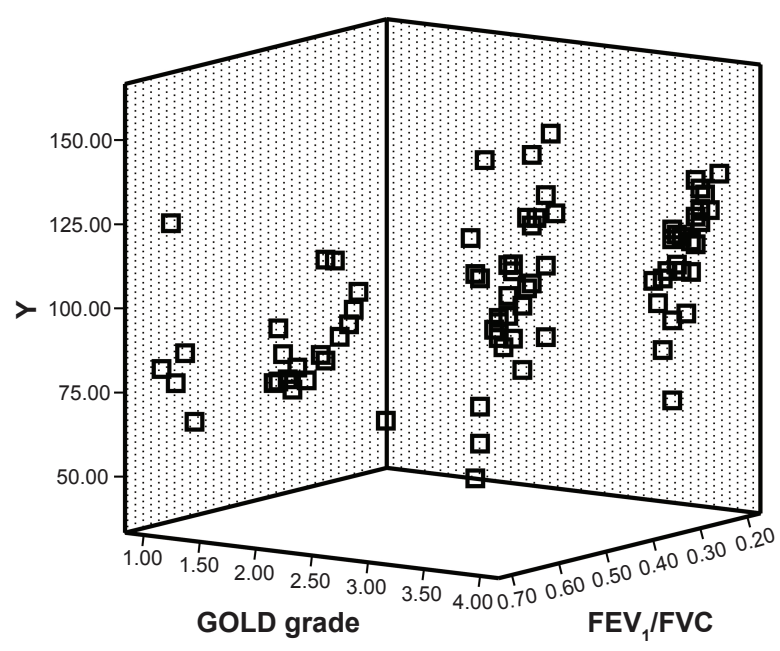

D

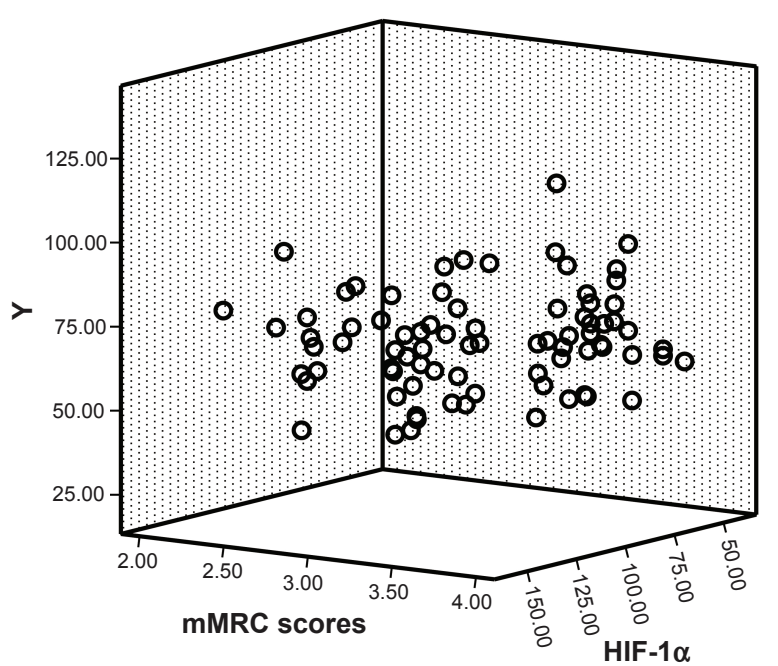

Figure 6 The clinical factors that affect the serum levels of HIF-I $\alpha$ and IL- 19 in stable COPD.

Notes: (A) The patient's FEV $/$ FVC and COPD grading correlated with the expression of HIF-I $\alpha(P<0.05)$. (B) Scatterplot suggested that the influence of FEV $/$ FVC on the expression of HIF- $\alpha \alpha$ was greater than that of GOLD grading. (C) The patient's mMRC scores and HIF-I $\alpha$ correlated with the expression of IL-I 9 (P<0.05). (D) Scatterplot suggested that the influence of HIF-I $\alpha$ on the expression of IL-19 was greater than that of mMRC scores.

Abbreviations: GOLD, Global Initiative for Chronic Obstructive Lung Disease; HIF-I $\alpha$, hypoxia-inducible factor I alpha; mMRC, modified British Medical Research Council.

may be a biological marker for the progression of COPD. IL-19 is cloned from B cells transformed from EB virus and has homologous gene products with IL- $10 .^{25}$ The monocytes treated by IL-19 can induce cells to produce IL- 6 , TNF- $\alpha$, and reactive oxygen metabolites, and these products may play key roles in promoting inflammation in the development of COPD. ${ }^{15}$ So, IL-19 may be a pro-inflammatory factor and correlates with inflammation progression in the development of COPD. Detecting the level of IL-19 in the blood of patients with COPD may help us understand the mechanism on occurrence and progression of the COPD.

Furthermore, we found that the serum levels of HIF- $1 \alpha$ and IL-19 showed a significant linear positive correlation. A previous study has shown that hypoxia acts on the cell oxygen receptors to induce a sustained expression of HIF- $1 \alpha$, and inflammation-related cytokines (interleukins) also 
play an important regulatory role on HIF-1 $\alpha$ expression. ${ }^{10}$ In addition, we noticed that the expressions of HIF- $1 \alpha$ and IL-19 were negatively correlated with pulmonary function in patients with stable COPD. Besides, the correlation between HIF- $1 \alpha$ and pulmonary function of COPD patients was greater than that of IL-19. Studies show that with the progress of COPD, hypoxemia of patients gradually deteriorates and shows an increase of expression of HIF-1 $\alpha$, which promotes pulmonary vascular remodeling and decreases the pulmonary function of COPD patients. ${ }^{11}$ Chronic airway inflammation plays an important role in the process of airway remodeling, airflow obstruction, and pulmonary hypertension in COPD. ${ }^{6}$ One study showed that activated adenosine A2B receptor induces human bronchial epithelial cells to release IL-19, and the latter can induce TNF- $\alpha$ release, suggesting that IL-19 plays a pro-inflammatory role in the occurrence and development of COPD. ${ }^{26}$ Our study showed that serum IL-19 of stable COPD patients was negatively correlated with the lung function of the patients, indicating that the pro-inflammatory effect of IL-19 may be related to the deterioration of lung function in COPD patients.

We used a multiple regression method to further disclose the relevant factors that may affect the expressions of HIF-1 $\alpha$ and IL-19. The results showed that the FEV $/$ FVC and COPD grading of patients significantly correlated with the expression of HIF-1 $\alpha$, and the influence of $\mathrm{FEV}_{1} / \mathrm{FVC}$ was greater than that of COPD grading. A study has shown that the value of $\mathrm{FEV}_{1} / \mathrm{FVC}$ is closely related to the severity of COPD, which is the main basis for the grading of COPD. ${ }^{17,20}$ Although the mMRC score is a subjective indicator, studies have shown that it can reflect the lung function status and biochemical quality of COPD patients. ${ }^{27,28}$ Our study showed that the patient's mMRC scores and the level of HIF-1 $\alpha$ were likely to affect the expression of IL-19 and the level of HIF- $1 \alpha$ appeared to have a closer correlation with the level of IL-19, indicating that the serum level of IL-19 in patients with COPD correlates with disease progression. Moreover, the results could imply that there was an inner correlation between the expressions of HIF-1 $\alpha$ and IL-19 in patients with stable COPD but its internal mechanism needs to be elucidated in future studies.

There are several inadequacies in the study. Firstly, the size of the study was limited. Secondly, selected patients came from several hospitals, which may lead to the patients' selective bias. Thirdly, the study only involves some observational indicators and lacks the research and analysis mechanism. Confirming the clinical reliability of the results requires further larger sample, multicenter studies.
In conclusion, serum HIF-1 $\alpha$ and IL-19 in stable COPD patients are upregulated and they have a linear positive correlation. In addition, the levels of HIF-1 $\alpha$ and IL-19 positively correlate with the GOLD grade, mMRC score, and clinical history of patients but negativity correlate with the pulmonary function of patients, suggesting that both of them could be used as indicators to help understand the occurrence and progression of COPD.

\section{Acknowledgment}

This study was supported by grants from the Scientific Research Plan projects of Shaanxi Province Education Department, China (grant no 17JK0661).

\section{Disclosure}

The authors report no conflicts of interest in this work.

\section{References}

1. Halpin DM, Miravitlles M, Metzdorf N, Celli B. Impact and prevention of severe exacerbations of COPD: a review of the evidence. Int J Chron Obstruct Pulmon Dis. 2017;12:2891-2908.

2. Cortopassi F, Gurung P, Pinto-Plata V. Chronic obstructive pulmonary disease in elderly patients. Clin Geriatr Med. 2017;33(4):539-552.

3. Zinellu E, Zinellu A, Fois AG, Carru C, Pirina P. Circulating biomarkers of oxidative stress in chronic obstructive pulmonary disease: a systematic review. Respir Res. 2016;17(1):150.

4. Adcock IM, Marwick J, Casolari P, et al. Mechanisms of corticosteroid resistance in severe asthma and chronic obstructive pulmonary disease (COPD). Curr Pharm Des. 2010;16(32):3554-3573.

5. Barnes PJ. Cellular and molecular mechanisms of asthma and COPD. Clin Sci. 2017;131(13):1541-1558.

6. Barnes PJ. Inflammatory mechanisms in patients with chronic obstructive pulmonary disease. J Allergy Clin Immunol. 2016;138(1):16-27.

7. Caramori G, Casolari P, Barczyk A, Durham AL, di Stefano A, Adcock I. COPD immunopathology. Semin Immunopathol. 2016;38(4): 497-515.

8. Sandau KB, Zhou J, Kietzmann T, Brüne B. Regulation of the hypoxiainducible factor 1 alpha by the inflammatory mediators nitric oxide and tumor necrosis factor-alpha in contrast to desferroxamine and phenylarsine oxide. J Biol Chem. 2001;276(43):39805-39811.

9. Yu ZG, Wang BZ, Cheng ZZ. The association of genetic polymorphisms of hypoxia inducible factor-1 alpha and vascular endothelial growth factor with increased risk of chronic obstructive pulmonary disease: A case-control study. Kaohsiung J Med Sci. 2017;33(9):433-441.

10. Mizuno S, Bogaard HJ, Gomez-Arroyo J, et al. MicroRNA-199a-5p is associated with hypoxia-inducible factor- $1 \alpha$ expression in lungs from patients with COPD. Chest. 2012;142(3):663-672.

11. Jiang H, Zhu Y, Xu H, Sun Y, Li Q. Activation of hypoxia-inducible factor-1 alpha via nuclear factor-kappa $B$ in rats with chronic obstructive pulmonary disease. Acta Biochim Biophys Sin. 2010;42(7):483-488.

12. Lin JR, Qin HH, Wang Y, Liang J, Xu JH, Jh X. Analysis of interleukin 19 serum levels and single nucleotide polymorphisms in systemic lupus erythematosus. Genet Mol Res. 2016;15(2).

13. Li L, Zheng-Qing Y, Juan-Yu H, et al. Association between interleukin-19 and angiopoietin-2 with vascular complications in type 2 diabetes. J Diabetes Investig. 2016;7(6):895-900.

14. Horiuchi H, Parajuli B, Wang Y, et al. Interleukin-19 acts as a negative autocrine regulator of activated microglia. PLOS ONE. 2015; 10(3):e0118640. 
15. Liao YC, Liang WG, Chen FW, Hsu JH, Yang JJ, Chang MS. IL-19 induces production of IL-6 and TNF-alpha and results in cell apoptosis through TNF-alpha. J Immunol. 2002;169(8):4288-4297.

16. Montes de Oca M, López Varela MV, Laucho-Contreras ME, et al. Classification of patients with chronic obstructive pulmonary disease according to the Latin American Thoracic Association (ALAT) staging systems and the global initiative for chronic obstructive pulmonary disease (GOLD). Arch Bronconeumol. 2017;53(3):98-106.

17. Vestbo J, Hurd SS, Agustí AG, et al. Global strategy for the diagnosis, management, and prevention of chronic obstructive pulmonary disease: GOLD executive summary. Am J Respir Crit Care Med. 2013;187(4): 347-365.

18. Vogelmeier CF, Criner GJ, Martinez FJ, et al. Global strategy for the diagnosis, management and prevention of chronic obstructive lung disease 2017 report: GOLD Executive Summary. Respirology. 2017;22(3):575-601.

19. Jain S, Self WH, Wunderink RG, et al. Community-acquired pneumonia requiring hospitalization among U.S. adults. $N$ Engl $\mathrm{J}$ Med. 2015;373(5):415-427.

20. Bellinger CR, Peters SP. Outpatient chronic obstructive pulmonary disease management: going for the GOLD. J Allergy Clin Immunol Pract. 2015;3(4):471-478.

21. Launois C, Barbe C, Bertin E, et al. The modified Medical Research Council scale for the assessment of dyspnea in daily living in obesity: a pilot study. BMC Pulm Med. 2012;12:61.
22. Lisspers K, Larsson K, Johansson G, et al. Economic burden of COPD in a Swedish cohort: the ARCTIC study. Int J Chron Obstruct Pulmon Dis. 2018;13:275-285.

23. Caramori G, Adcock IM, di Stefano A, Chung KF. Cytokine inhibition in the treatment of COPD. Int J Chron Obstruct Pulmon Dis. 2014;9: $397-412$.

24. Baz-Dávila R, Espinoza-Jiménez A, Rodríguez-Pérez MC, et al. Role of HIF1A, VEGFA and VEGFR2 SNPs in the susceptibility and progression of COPD in a Spanish population. PLOS ONE. 2016; 11(5):e0154998

25. Fujimoto Y, Fujita T, Kuramoto N, et al. The role of interleukin-19 in contact hypersensitivity. Biol Pharm Bull. 2018;41(2):182-189.

26. Zhong H, Wu Y, Belardinelli L, Zeng D. A2B adenosine receptors induce IL-19 from bronchial epithelial cells, resulting in TNF-alpha increase. Am J Respir Cell Mol Biol. 2006;35(5):587-592.

27. Huang WC, Wu MF, Chen HC, Hsu JY, TOLD Group. Features of COPD patients by comparing CAT with MMRC: a retrospective, crosssectional study. NPJ Prim Care Respir Med. 2015;25:15063.

28. Kim S, Oh J, Kim YI, et al. Differences in classification of COPD group using COPD assessment test (CAT) or modified Medical Research Council (mMRC) dyspnea scores: a cross-sectional analyses. BMC Pulm Med. 2013;13:35.
International Journal of COPD

\section{Publish your work in this journal}

The International Journal of COPD is an international, peer-reviewed journal of therapeutics and pharmacology focusing on concise rapid reporting of clinical studies and reviews in COPD. Special focus is given to the pathophysiological processes underlying the disease, intervention programs, patient focused education, and self management protocols.

\section{Dovepress}

This journal is indexed on PubMed Central, MedLine and CAS. The manuscript management system is completely online and includes a very quick and fair peer-review system, which is all easy to use. Visit http://www.dovepress.com/testimonials.php to read real quotes from published authors. 